\title{
Surgical Approach in Craniofacial Fibrous Dysplasia: Case Report and Integrative Review
}

\begin{abstract}
Romildo José de Siqueira Bringel1,2, Ivo Cavalcante Pita Neto1,2, Jéferson Martins Pereira Lucena Franco ${ }^{1}$, Ricardo José de Holanda Vasconcellos ${ }^{3}$, Fernando Bastos Pereira Júnior ${ }^{4}$, Daniela Neves Bringel ${ }^{5}$, Manoel de Jesus Rodrigues Mello ${ }^{6}$, Renato Luiz Maia Nogueira7, Luciano Miller Reis Rodrigues ${ }^{2}$
\end{abstract}

\section{Abstract}

Fibrous dysplasia is a benign and pseudoneoplasic osteopathy with slow progression, characterized by the replacement of normal bone by an excessive proliferation of fibrous connective tissue cell, interspersed with irregular bone trabeculae. In general, it affects 1 between 4,000 to 10,000 individuals living births. This is a not familiar, congenital disorder, which produces around $2.5 \%$ of all bone tumors and more than $7 \%$ of all non-malignant bone tumors. This article aims to report a clinical case of monostotic fibrous dysplasia in jaw, proceeding with its surgical correction and to make a review of literature, describing the most important features and the major controversies.

Keywords

Monostotic Fibrous Dysplasia; Polyostotic Fibrous Dysplasia; Fibrous Dysplasia; Jaw; Craniofacial.

\section{Introduction}

Fibrous dysplasia is a benign and pseudoneoplasic osteopathy with slow progression, characterized by the replacement of normal bone by an excessive proliferation of fibrous connective tissue cell, interspersed with irregular bone trabeculae [1]. In general, it affects 1 between 4,000 to 10,000 individuals living births. This is a not familiar, congenital disorder, which produces around $2.5 \%$ of all bone tumors and more than $7 \%$ of all non-malignant bone tumors $[2,3]$. 
This disorder was first described as "general fibrous osteitis" by Von Recklinghausen, in 1891, in a patient with skeletal deformity due to bone fibrotic changes. However, only in 1938 this condition was known as "fibrous dysplasia", when Lichtenstein introduced the term $[4,5]$.

Regarding its aetiology, fibrous dysplasia is a sporadic condition, resulting from a post-zygotic mutation on gene GNAS 1 (guanine nucleotide-linked protein, Alpha stimulating activity of polypeptide), coding for the subunit of signal transduction $G$ (GS-a) leading to increased production of c-AMP affecting the proliferation and differentiation of preosteoblasts $[6,7,8]$. Presumably, the clinical severity of the condition depends on the time of fetal life or of postnatal life in which the mutation of the GNAS 1 happens. Therefore, it is said that, when the mutation occurs during the period of embryonic life, the expected result will be multiple bone lesions of fibrous dysplasia, and also skin and endocrine abnormalities. However, if the mutation happens during postnatal life, the progeny of the modified cells will be essentially confined to one location, resulting in fibrous dysplasia that affects a single bone $[1,9]$.

Thus, the fibrous dysplasia is divided into two groups, varying as to its form of presentation: monostotic and polyostotic. Themonostotic form is characterized by the involvement of a single bone or contiguous bones. It is considered the most common form, corresponding to $70 \%$ of cases, without prevalence by sex and with fondness for gnathic bones. In the vast majority of the time, growth of lesions stops with the closure of growth plate $[10,3]$.

Polyostotic formis characterized by the involvement of two or more bones without continuity, and represents approximately $30 \%$ of all cases, showing higher prevalence in the female gender. The clinical manifestations are early and with insidious onset, and may attend with bone pain. When this form of fibrous dysplasia is associated with café-au-lait skin pigmentation and endocrinopathy, they are called syndrome of McCuneAlbright [10, 11].

Fibrous Dysplasia treatment consists primarily in aesthetic surgical procedure, aiming at improvement of facial asymmetry and/or facilitation of the prosthetic rehabilitation and clinical and radiographic follow-up. Being a benign lesion with rare cases of malignant transformation, surgical removal of injury may not be indicated, because, besides causing a severe facial deformity, can cause a pathological fracture of the region, due to the weakening of this. For these reasons, the majority of patients are treated simply by surgical removal of part of the lesion. In certain cases, it is better to wait for the bone growth plate closure since the injury, even if slowly, continues to grow. Statistically about 25 to $50 \%$ of the young patients surgically treated present recurrences after surgical treatment of osteoplasty of the lesion $[1,2,3,4$, $5,6,7,8,10,11]$.

This article aims to present a clinical case of monostotic fibrous dysplasia in jaw, proceeding with its surgical correction and to make a review of literature, describing the most important aspects and the major controversies.

\section{Methodology:}

Electronic search through the National library of Medicine (Pubmed; www.punmed.gov) was held on the case reports of Craniofacial Fibrous Dysplasia, from January 1984 to January 2016.

The following medical issues specific titles and keywords were used: (monostotic fibrous dysplasia [MeSH Terms] OR polyostotic fibrous dysplasia [MeSH Terms] and fibrous dysplasia [Title/Abstract] and jaw [MeSH Terms]) craniofacial [MeSH Terms] $\mathrm{OR})$.

The studies were included only if all of the following eligibility criteria were met: 1) Publications in English; 2) case report; 3) human species 4) In- 
volvement of the maxillofacial complex. The other articles that did not meet the inclusion criteria were excluded (Figura 1)

21 articles met the criteria and all the data were extracted and tabulated (Graphs 1 and 2).

\section{Results:}

The ages of the 21 cases ranged from 10 to 72 years, with an average of 29.8 years old. Most of the cases were female, representing (47.6\%). The maxilla was the bone more commonly observed ( $n$ -
$13 ; 61.9 \%)$, followed by the Mandible (n-8), that can be isolated or associated with other bones. The conservative treatment was most commonly observed (38\%), followed by surgical treatment with marginal resection (23\%). Monostotic fibrous dysplasia was the most common (n-15), representing (71\%) of cases, followed by polyostotic fibrous dysplasia ( $n-3)$ and polyostotic fibrous dysplasia McCune-Albright syndrome-associated $(\mathrm{n}-2)$, representing in their entirety (23.8\%) (Table 1).

Figure 1: Flowchart from PubMed using the MeSH terms "Monostotic fibrous dysplasia" OR "Polyostotic fibrous dysplasia" AND "Fibrous dysplasia" AND "Jaw" OR "Craniofacial" and Title/Abstract "Fibrous dysplasia".

Search (monostotic fibrous dysplasia[MeSH Terms]) OR polyostotic fibrous dysplasia[MeSH Terms]) AND fibrous dysplasia[Title/Abstract]) AND jaw[MeSH Terms]) OR craniofacial[MeSH Terms])

\section{Articles}

21 articles InclusionCriteria:

Case Report Englishlanguage Humanspecies

\section{Excluded Articles.}

Graph 1: Fibrous dysplasia articles per year.

\section{- Total Per Yea}

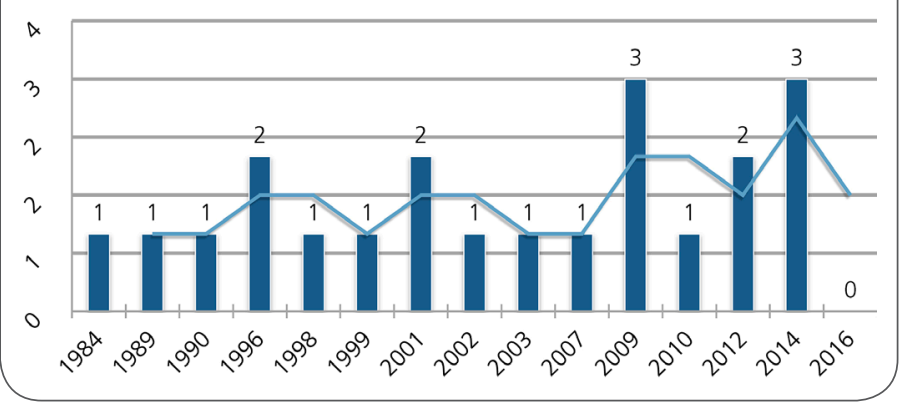

Graph 2: Cumulative chart of fibrous dysplasia.

\section{Cumulative}

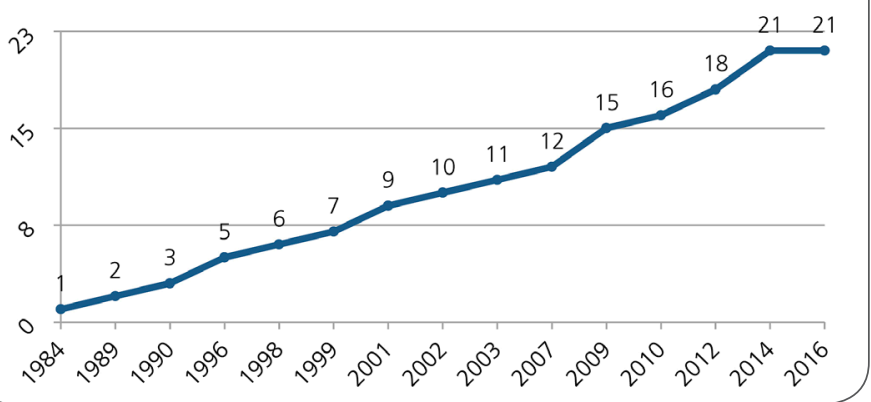

Table 1. Articles selected from search in PubMed.

\begin{tabular}{|l|c|c|c|c|c|c|c|}
\hline \multicolumn{1}{|c|}{ Author } & Year & Sex & Localization & Age $\begin{array}{c}\text { Number } \\
\text { of cases }\end{array}$ & Treatment & Classification \\
\hline Villar et al. [12] & 2014 & F & Mandible & 33 & 1 & ST - MR \\
\hline Petrocelli et al. [13] & 2014 & F & $\begin{array}{c}\text { Orbital contour, Maxilla } \\
\text { and Mandible }\end{array}$ & N/A & 1 & CT - DIR \\
\hline $\begin{array}{l}\text { Carini et al. [14] } \\
\text { Cherkaoui et al. [15] }\end{array}$ & 2014 & F & Palat & 60 & 1 & CT \\
\hline
\end{tabular}




\begin{tabular}{|c|c|c|c|c|c|c|c|}
\hline Author & Year & Sex & Localization & Age & $\begin{array}{l}\text { Number } \\
\text { of cases }\end{array}$ & Treatment & Classification \\
\hline Araújo et al. [16] & 2012 & $\mathrm{~F}$ & Mandible & 24 & 1 & $S T-M R$ & $\begin{array}{c}\text { PFD - McCune- } \\
\text { Albright }\end{array}$ \\
\hline Nambi et al. [17] & 2010 & M & Maxilla & 25 & 1 & CS & MDF \\
\hline Tambe et al. [18] & 2009 & $\mathrm{~F}$ & Zygomatic and Maxilla & 60 & 1 & DA & MDF \\
\hline Choi et al. [19] & 2009 & N/A & N/A & $\mathrm{N} / \mathrm{A}$ & 5 & CS & $\mathrm{N} / \mathrm{A}$ \\
\hline Alvares et al. [20] & 2009 & $\mathrm{M}$ & Maxilla & 23 & 1 & $\mathrm{CT}$ & MFD \\
\hline Slutsky-Goldberg et al. [21] & 2007 & M & Maxilla & 14 & 1 & $\mathrm{CT}$ & MFD \\
\hline Yasuokaet al. [22] & 2003 & $\mathrm{~F}$ & Maxilla & 10 & 1 & $\mathrm{CT}$ & MFD \\
\hline Kim et al. [23] & 2002 & M & Maxilla & 18 & 1 & $\mathrm{CT}$ & MFD \\
\hline Tokano et al. [24] & 2001 & M & Maxilla & 12 & 1 & $\mathrm{CT}$ & MFD \\
\hline Zenn. [25] & 2001 & N/A & Mandible & $\mathrm{N} / \mathrm{A}$ & 1 & $S T-M R$ & MFD \\
\hline Avril et al. [26] & 1999 & $\mathrm{~F}$ & $\begin{array}{c}\text { Maxilla, Orbital and } \\
\text { Ethmoid }\end{array}$ & 37 & 1 & $S T-M R$ & MFD \\
\hline Gurler et al. [27] & 1998 & $\mathrm{~F}$ & $\begin{array}{c}\text { Mandible, Zygomatic and } \\
\text { Maxilla }\end{array}$ & 11 & 1 & PRE & $\begin{array}{c}\text { PFD - McCune- } \\
\text { Albright }\end{array}$ \\
\hline Arik et al. [28] & 1996 & M & Maxilla and Mandible & 26 & 1 & $\mathrm{CT}$ & PFD \\
\hline Feingold et al. [29] & 1996 & $\mathrm{~F}$ & Mandible & $\mathrm{N} / \mathrm{D}$ & 1 & ST - MR & MFD \\
\hline Forman et al. [30] & 1990 & N/D & $\mathrm{N} / \mathrm{D}$ & $\mathrm{N} / \mathrm{D}$ & 1 & $N / D$ & PFD \\
\hline Bessho et al. [31] & 1989 & $\mathrm{~F}$ & Mandible & 72 & 1 & $\mathrm{TC}$ & MFD \\
\hline Sellu et al. [32] & 1984 & N/D & Maxilla & N/D & 1 & $\mathrm{TC}$ & MFD \\
\hline
\end{tabular}

CS - Conservative surgery; CT - Conservative Treatment; DA - Dacryocystorhinostomy; DIR - Dental implant rehabilitation; F - Female; MR Marginal Resection; M- Masculine; MFD - Monostotic Fibrous Dysplasia; N/A - Not Available; PFD - Polyostotic Fibrous Dysplasia; PR - Prosthetic reconstruction; PRE - Partical resection; ST - Surgical Treatment.

\section{Case report}

Patient M.F.B, feoderm, 22 years old, female, attend the Oral and Maxillofacial Surgery and Traumatology service of the Hospital São Vicente de Paulo (HMSVP) in Barbalha-CE, Brazil, reporting bulging and algic symptoms that started 12 months earlier in the region of the left mandible. In the clinical examination, it was found that she featured general health standards of normality, flushed, hydrated, afebrile, without tangible adenomegaly, denoting volumetric expansion in the cheek region, hard to palpation, with absence of crepitation and mobility, with covering skin showing aspect of normality, bucco-lingual expansion without facial and mandibular dental midline deviation. In the oral ca- vity examination, it was observed a discreet bone bulging more accentuated by vestibular, in the alveolar left lower edge region, fibromucosa, which featured healthy aspect and normal coloring, presence of dental element in position of a impacted tooth, localized dental absence with dental remaining in good condition (Figure 2).

It was noted in the radiographic examination densely diffuse radiopaque area, irregular trabeculae, small areas of bone rarefaction, discreet periosteal calcification, endothelial osteolytic lesions, thinning and bulging of the cortical, presence of radiopaque halo around with mixed aspect (Figure 3).

Initially, the realization of an incisional biopsy was chosen, since it was an extensive lesion and exten- 
Figure 2: Facial and oral examination aspects of the patient showing volumetric expansion in the left mandibular region.
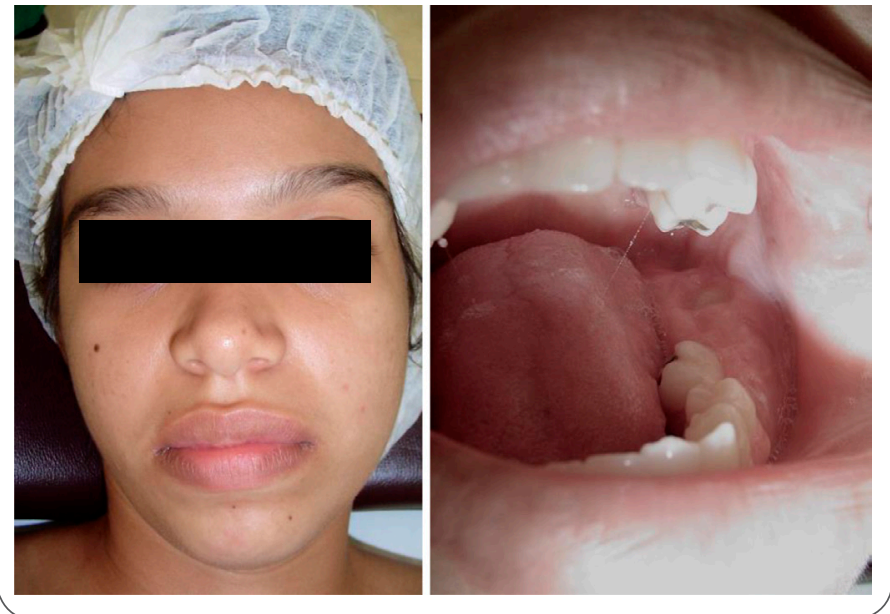

Figure 3: A) Preoperative panoramic radiography with symmetrical jaw measurement using image analysis.

B) The inferior contours of both sides were tracked, and then the traits were superimposed. The value of the area contained by two contour lines was defined as differential area.
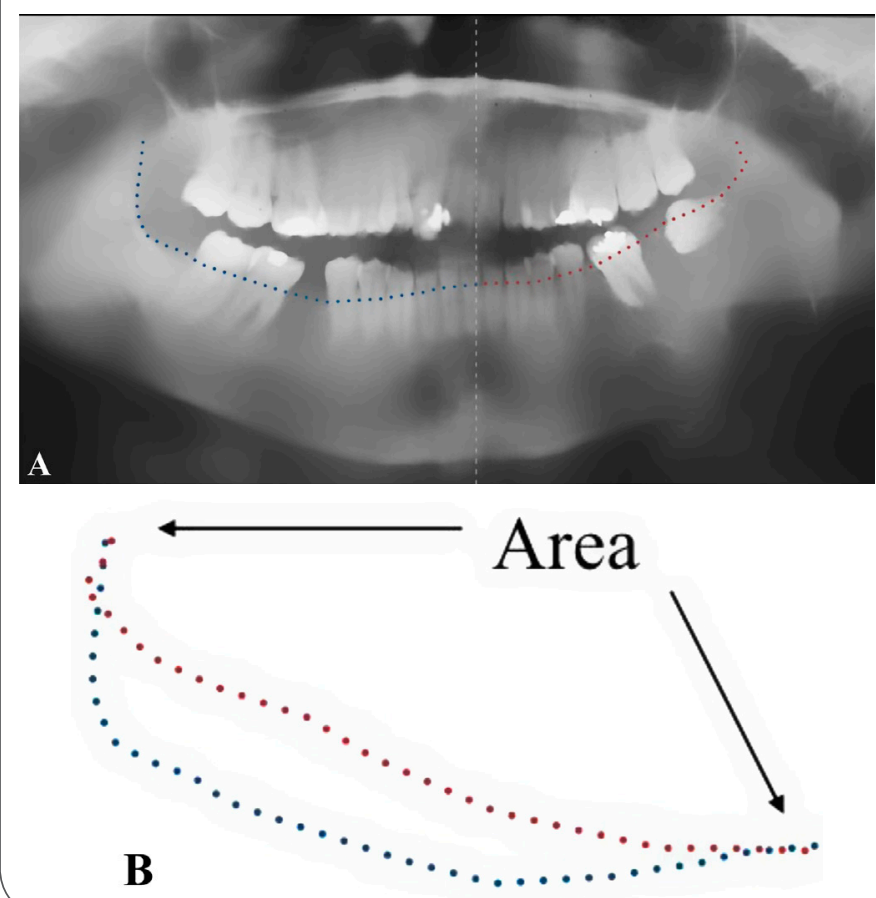

Figure 4: Transoperative clinical aspect of the patient showing the osteoplasty of the mandible by intraoral approach.

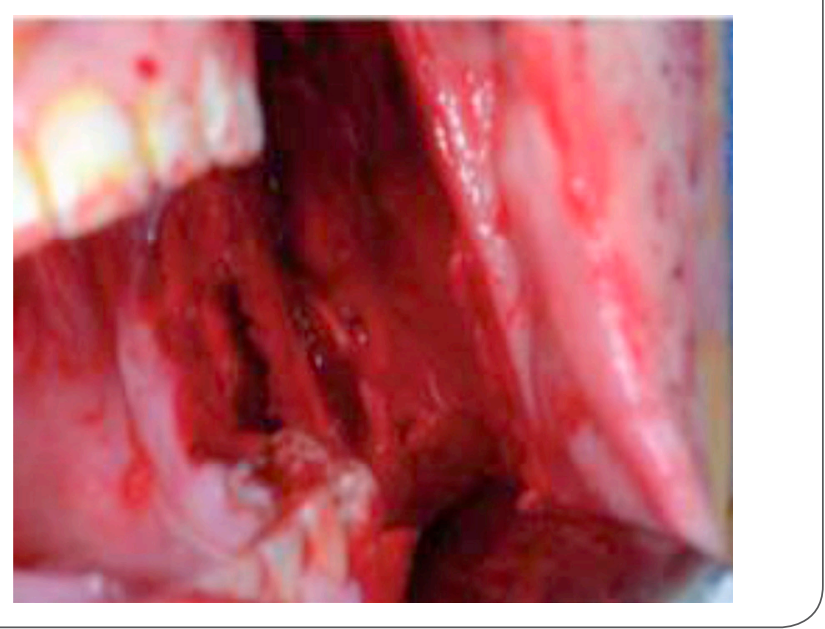

Figure 5: Intraoral clinical aspect of the patient, immediate postoperative.

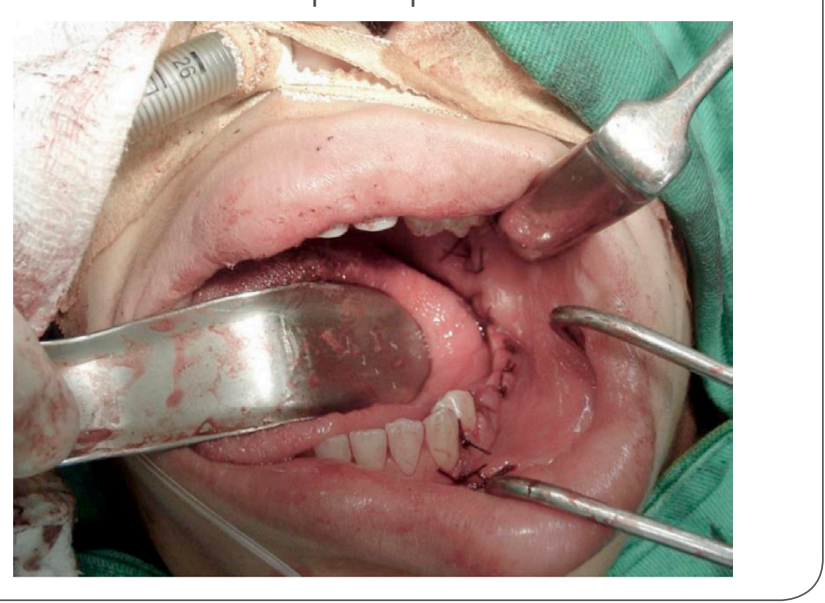

Figure 6: Intra and extraoral postoperative clinical aspect of the patient.

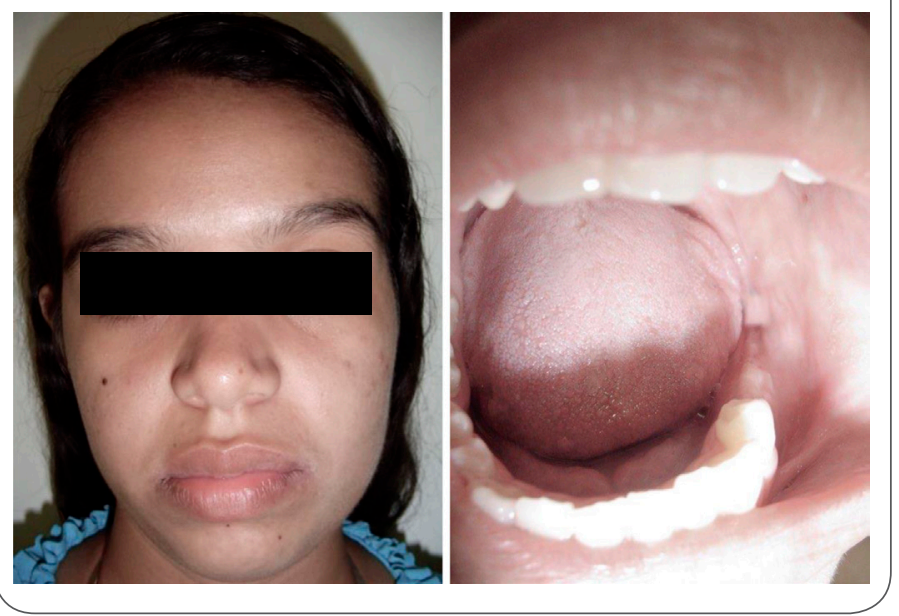


Figure 7: A) postoperative panoramic radiography with symmetrical jaw measurement using image analysis

B) The inferior contours of both sides were tracked, and then the traits were superimposed. The value of the area contained by two contour lines was defined as differential area.
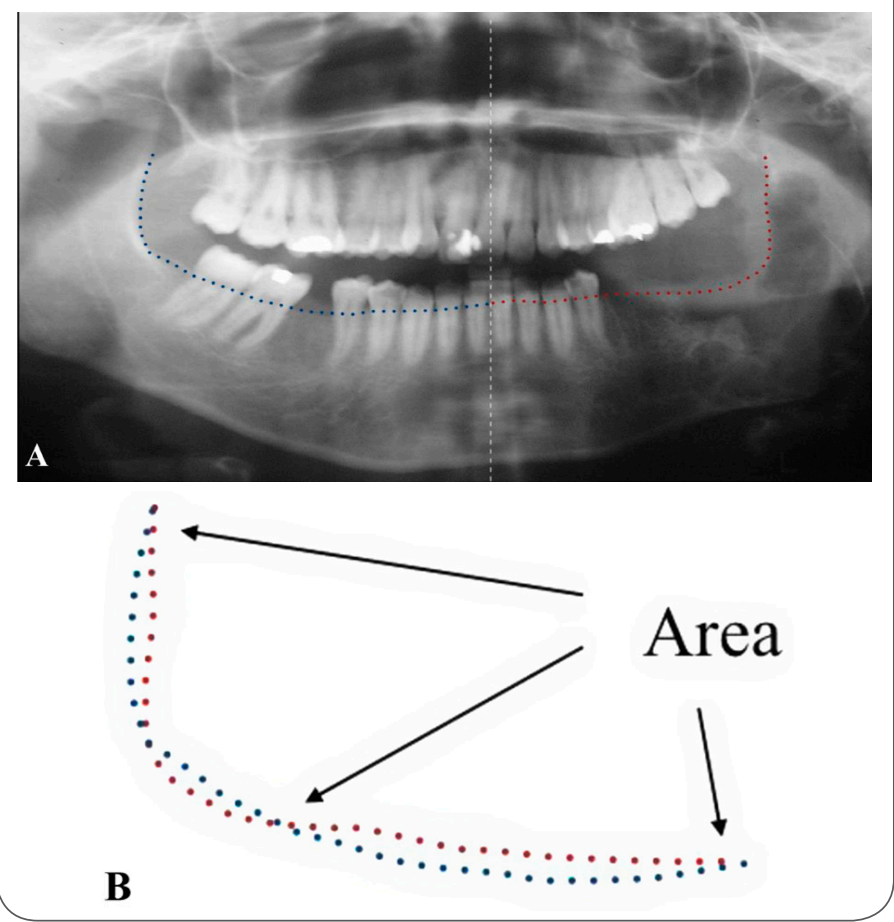

sive surgical approach. The collection of material was performed in the Oral and Maxillofacial clinic, at the HMSVP/CE, under local anaesthesia, with the patient medicated and orientated about the postoperative care. The result of the histopathological examination was monostotic bone fibrous dysplasia, record: BO6 15512.

Given the clinical and radiographic findings, surgical approach was proposed for osteoplasty with the intention of remodelling the affected region for symmetrisation of the lower face, proceeded under general anaesthesia and tracheal intubation. Initially, dental elements 36 and 38 were carefully removed, following up with intraoral approach in the fornix of the vestibule, starting posteriorly near pterigomandibular preaches and anteriorly extending between the premolar and the canine proceeded with mucoperiosteal displacement and exposure of the injury.

Through advanced planning, the delimitation of the area to be osteotomized was done with small trepanation using spherical surgical drill, joined posteriorly both the longitudinal and transversal directions, facilitating the removal of the lesion in small fragments, proceeded with the removal of part of the injury by using chisel (Figure 4). In conclusion, the bone surfaces were smoothed with osteotome and surgical cutter, thereby performing local osteoplasty (Figure 5).

In 10 months postoperative follow-up, the patient is with re-aesthetic-functional stabilization, without clinical signs of recurrence, expressing intense satisfaction with the results obtained (Figure 6). In panoramic radiographic postoperative analysis, it was found maintenance of the mandibular contour, with absence of recurrence so far (Figure 7).

\section{Discussion:}

Fibrous Dysplasia is an uncommon pathology, congenital, benign, characterized by the replacement of the normal bone by fibrous tissue, with mineralized osteoid beams, representing $2.5 \%$ of bone tumors and $7.7 \%$ of benign bone tumors [1, 20, 21, 22, $33,34]$.

The craniofacial region is an important site of involvement of Fibrous Dysplasia, especially the maxilla and the mandible. Typically, lesions of the mandible are believed to be truly monostotic, however, the maxilla injuries often involve the adjacent bones like occipital, sphenoid, zygomatic, palatine, ethmoid, nasal and temporal, which defines the polyostotic form $[1,35]$. In agreement with the case in question and with the review carried out, in which it was found that $71 \%$ of the reported cases were of monostotic Fibrous Dysplasia and $23.8 \%$ of polyostotic, being the maxilla the most commonly affected bone, representing $61.9 \%$ of the cases surveyed (Table 1) 
Radiographically, the Fibrous Dysplasia can be classified into compact, lithic and mixed forms. The compact form is characterized by the progressive replacement of the normal bone by fibrous tissue, with image comparable to frosted glass, representing $50 \%$ of the cases. The lithic form is more often found in the skullcap and facial bones. CT scan shows radiolucent lesion, surrounded by halo with high density, presenting irregular edges. Finally, the mixed form is characterized by the presence of radiopaque areas alternated with radiolucent areas to computed tomography $[2,6,33]$. It was observed in the clinical case reported compact Fibrous Dysplasia

\section{(Figure 3).}

The treatment of Fibrous Dysplasia is a controversial topic. Some authors advocate conservative treatment, by the absence of symptoms and aesthetic complaints. The surgical indication is based on complaints and in the degree of commitment of the patients, being more predictable after stability in the evolution of the disease and more urgent when it involves noble structures, as well as systemic impairment $[6,36,37]$. In our study, we observed that the conservative treatment was the most commonly adopted, representing 38\% of the evaluated cases, followed by surgical treatment with marginal resection (23\%) (Table 1).

The use of surgical approach in treatment of monostotic Fibrous Dysplasia in mandible has been described as an effective alternative in resolving such cases, thus it should be indicated, taking into account the clinical course and the symptoms presented, performed preferably after puberty or end of bone maturation, because of the pathophysiology of fibrous dysplasia.

\section{Conclusion}

Discrepancies were found in the literature and it was concluded that the craniofacial fibrous dysplasia is a bone pathology that needs further study to fill the existing gaps.
Surgery is considered the most effective treatment to control their symptoms and deformity. Surgical indication is based on the degree of commitment and complaints by patients, being more predictable after bone maturation and more urgent when it involves important structures.

\section{References}

1. Santos, JN.; Vieira, TSLS.; Góis Filho, DM.; Vasconcelos, SJA.; Azevedo, RA. Fibrous dyplasia: Osteoplasty using the WeberFerguson approach. A case report. Rev. Cir. Traumatol. BucoMaxilo-Fac, 2010; v.10(1), p.70-80.

2. Costanzi, MA.; Cruz, AAV. McCune Albringht syndrome diffuse orbital involvent due to fibrous dysplasia: a case report. Arq Bras Oftalmol, 2007; v.70(2), p.1021-3.

3. Delibasi, C.; Deniz, E.; Ekici, ID. Monostotic Fibrous Dysplasia of the Mandible. OHDM, 2014; v.13(2), p. 326-329.

4. Lichtenstein L. Polyostotic fibrous dysplasia. Arch Surg, 1938; v.38, p.874-98.

5. Menon, S.; Venkatswamy, S.; Ramu, V.; Banu, K.;Ehtaih, S.; Kashyap, VM. Craniofacial Fibrous dysplasia: Surgery and literature review. Annls of Maxillofacial Surgery, 2013; v.3, p.66-71.

6. Alonso, N.; Matushita, H.; Alessi, MS. Surgical approach to the treatment of craniofacial fibrous dysplasia - A 14 - year experiencedysplasia - 14 years experience. Rev. Bras. Cir. Plást, 2014; v.29(1), p.66-70.

7. MacDonal-Jankowski, D. Fibrous Dysplasia: a systematic review. Dentomaxillofacial Radiology, 2009; v.38, p.196-215.

8. Pagotto, LEC.;Mariani, PB. Monostotic Fibrous Dysplasia of the Maxilla: a Review of the literature and reporto of 2 casos. Rev. Cir. Traumatol. Buco-Maxilo-Fac, 2009; v.(9), p.23-32.

9. Uppala, D.; Majumdar, S.; Rao, AK.;Biswas, S. Monostotic Fibrous Dysplasia of Maxilla. Oral and Maxillofacial Pathology Jounal, 2015; v.6(2), p.628-631.

10. Botelho, RA.;Tornin, OS.; Yamashiro, I.; Menezes, MC.; Furlan, S.; Ridelenski, M.; Yamashiro, R.; Chagas, JFS.; Sousa, RP. Characteristics of fibrous dysplasia tomographic craniofacial: retrospective study of 14 cases. Radiol Bras, 2006; v.39(4), p.268-272.

11. Salenave, S.; Boyce, AM.; Collins, MT.; Chanson, P. Acromegaly and McCune-Albright Syndrome. J Clin Endocrinol Metab, 2014; v.99(6), p.1955-1969.

12. Villar, P.R.; Ramos, M.B. Virtual surgical planning for extensive fibrous dysplasia in the mandible. Aesthetic Plast Surg, 2014; v. 38(5), p. 941-5. 
13. Petrocelli, M.; Kretschmer, W. Conservative treatment and implant rehabilitation of the mandible in a case of craniofacial fibrous dysplasia: a case report. J Oral Maxillofacial Surg, 2014; v. 72(5), p. 902.e1-902.e6

14. Carini, F.; Saggese, V.; Porcaro G, Baldoni, M. Treatment of craniofacial fibrous dysplasia: a case report. Minerva Stomatol, 2014;v. 63(1-2), p. 43-9.

15. Cherkaoui, A.; Nawar, O.; Fouad, I.; Najib, B.; El, A.N. Prosthetic reconstruction after surgical resection of fibrous dysplasia of the maxillary and palatine bone. West Indian J, 2012; v. 61(3), p. 299-301.

16. Araújo, P.I.; Soares, V.Y.; Queiroz, A.L.; Santos, A.M.; Nascimento, L.A. Sarcomatoustransformation in the McCune-Albright syndrome. Oral Maxillofac Surg, 2012; v. 16(2), p. 217-20.

17. Nambi, G.I.; Jacob, J.; Gupta, A.K. Monofocal maxillary fibrous dysplasia with orbital, nasal and oral obstruction. J Plast Reconstr Aethet Surg, 2010; v. 63(1), p. 16-8.

18. Tambe, K.; Vydianath, S.R.; Mudhar, H.S.; Sandramouli, S. Successful treatment of nasolacrimal duct obstruction secondary to fibrous dysplasia by external dacryocystorhinostomy with mitomycin C. Ophthal Plast Reconstr Surg, 2009; v.25(2), p. 164-5.

19. Choi, J.W.; Lee, S.W,;Koh, K.S. Correction of proptosis and zygomaticomaxillary asymmetry using orbital wall decompression and zygoma reduction in craniofacial fibrous dysplasia. J Craniofac Surg, 2009; v. 20(2), p. 326-30.

20. Alvares, L.C.; Capelozza, A.L.; Cardoso, C.L.; Lima, M.C.; Fleury, R.N.; Damante, J.H. Monostotic fibrous dysplasia: a 23-year follow-up of a patient with spontaneous bone remodeling. Oral Surg Med Oral Pathol Oral Radiol Endod, 2009; v. 107(2), p. 229-34.

21. Slutzky-Goldberg, I.; Helling, I. Healing of a fibrous dysplastic lesion in a permanent molar after endodontic therapy. J Endod, 2007; v. 33(3), p. 314-7.

22. Yasuoka, T.; Takagu, N.; Hatakeyama, D.; Yokoyama, K. Fibrous dysplasia in the maxilla: possible mechanism of bone remodeling by calcitonin treatment. Oral Oncol, 2003; v. 39(3), p. 301-5.

23. Kim, H.J.; Kim, K.D.; Lee, M.H. Becker's melanosis associated with fibrous dysplasia. Int J Dermatol, 2002; v. 41(7), p. 384-6.

24. Tokano, H.; Sugimoto, T.; Noguchi, Y.; Kitamura, K. Sequential computed tomography images demonstrating characteristic changes in fibrous dysplasia. J Laryngol Otol, 2001; v. 115(9), p. 757-9.

25. Zenn, M.R.; Zuniga, J. Treatment of fibrous dysplasia of the mandible with radical excision and immediate reconstruction: case report. J Craniofac Surg, 2001; v. 12(3), p. 259-63.

26. Avril, M.F.; Eloy, J.P.; Panosetti, E. Fibrous dysplasia of the maxillary: a case report. Acta Otorhinolaryngol Belg, 1999; v. 53(2), p. 133-6.

27. Guler, T.; Alper, M.; Gençosmanoglu, R.; Totan, S.; Guner, U.; Akin, Y. McCune-Albright syndrome progressing with severe fibrous dysplasia. J Craniofac Surg, 1998, v. 9(1), p. 79-82.
28. Arilk, N.; Biriken, D.; Akpolat, T.; Sungur, C.; Coskun, C.; Basoglu, T.; Keskin, M.; Sahin, M.; Toller, M.O. Severe hyperparathyroidism associated with fibrous dysplasia: a case report. Nephron, 1996; v. 74(2), p. 481-2.

29. Feingold, R.S.; Argamaso, R.V.; Strauch, B. Free fibula flap mandible reconstruction for oral obstruction secondary to giant fibrous dysplasia. Plast Reconstr Surg, 1996; v. 97(1), p.196-201.

30. Forman, D.; Leiblich, S.; Berger, J.; Gold, B.D. Unusual treatment of an aggressive polyostotic fibrous dysplasia with a 3-year follow-up. Oral Surg Oral Med Oral Pathol, 1990; v. 70(2), p. 150-4.

31. Bessho, K.; Tagawa, T.; Murata, M.; Komaki, M. Monostotic fibrous dysplasia with involvement of the mandibular canal. Oral Surg Oral Med Oral Pathol, 1989; v. 68(4), p. 396-400.

32. Sellu, D.P.; Hopkins, N.F. Monostotic fibrous dysplasia of the maxilla--one patient followed up for nine-years. Br J Clin Pract, 1984; v. 38(11-12), p. 425-8.

33. Alves, A.L.; Canavarros, F.; Vilela, D.S.A.; Granato, L.; Préspero, J.D. Fibros Displasia: Reportthee cases. Rev Bras Otorrinolaringol, 2002; v. 68(2), p. 288-92.

34. Ricaldo, P.; Horswell, B.B. Craniofacial brous dysplasia of the fronto-orbital region: a case series and literature review. J Oral Maxillofac Surg, 2001; v. 59(2), p. 157-67.

35. Flores, J.A.M.; Ferrari, M.D.; Koltermann, V.; Castellanos, C. C.; Oliveira, G.D.; Araújo, D.F. Fibrousdysplasia of Mandible. AMRIGS, 2010; v. 54(1), p. 77-80

36. Júnior, V. S.; Andrade, E.C..; Didini, A.L.S.; Jorge, J.C.; Filho, N.S.; Yoshimoto, F.R. Fibrous Dysplasia of the tempotal bone: a case report and review of the literature. Revista Brasileira de Otorrinolaringologia, 2004; v. 70(6), p. 828-31.

37. Pita-Neto, I.C.; Araujo-Junior, J.L.; Santana, M.D.R.; Batista, H.M.T.; Soares, E.C.S.; Abreu, L.C.; Rodrigues, L.M.R.; Pinheiro, W.R.; Almeida, G.S. Craniofacial Fibrous Dysplasia Addressed Through the Intraoral and Nasal Access. International Archives of Medicine, 2015; v. 8, p. 1-7

\section{Publish in International Archives of Medicine}

International Archives of Medicine is an open access journal publishing articles encompassing all aspects of medical science and clinical practice. IAM is considered a megajournal with independent sections on all areas of medicine. IAM is a really international journal with authors and board members from all around the world. The journal is widely indexed and classified Q1 in category Medicine. 